Anales de Geografía de la Universidad Complutense ISSN: 0211-9803

https://dx.doi.org/10.5209/aguc.79340

\title{
La problemática del tráfico ilegal de cocaína desde un enfoque multiescalar y multiterritorial
}

\author{
Ana Lía Guerrero ${ }^{1}$; Lorena C. Espasa ${ }^{2}$ \\ Recibido: 2 de mayo del 2020 / Enviado a evaluar: 26 de septiembre del 2020 / Aceptado: 10 de diciembre del 2021
}

Resumen. El objetivo del presente trabajo es analizar la problemática global del tráfico ilegal de cocaína, desde un enfoque multiescalar y multiterritorial que identifi-que las dinámicas emergentes y sus articulaciones multiescalares. Se emplea un enfoque cualitativo basado en el método inductivo que se complementa con consulta de fuentes secundarias, como informes de organismos oficiales y prensa escrita que permitan profundizar el análisis y comprensión de la pro-blemática. Se aborda el estudio a través del renovado marco teórico de la Geo-grafía Política y la Geografía Económica, rescatando principalmente las ideas propuestas por Haesbaert (2013) acerca de la multiterritorialidad y la movili-dad y, por Sack (1986) sobre el control del territorio. En cuanto a los resulta-dos de la investigación, se destaca la necesidad de adoptar un enfoque territo-rial integrador que permita comprender mejor las formas en que operan e in-teractúan estas economías ilegales, en la superposición de territorios legales e ilegales.

Palabras clave: Geografías Ilegales; tráfico de cocaína; enfoque multiterritorial y multiescalar; Región Sudamericana y Caribe.

\section{[en] The problem of illegal cocaine trafficking from a multiscalar and multiterritorial approach}

Abstract. The aim of this paper is to analyze the global problem of illegal cocaine traf-ficking, from a multi-scale and multi-territorial approach that identifies the emerging dynamics and their multi-scale articulations. A qualitative approach based on the inductive method is used, which is complemented by consultation with secondary sources, such as reports from official organizations and the written press,

1 Departamento de Geografía y Turismo (DGyT). Universidad Nacional del Sur (UNS). Bahía Blanca. (Argentina)

E-mail: aguerrero@uns.edu.ar

2 Departamento de Geografía y Turismo (DGyT). Universidad Nacional del Sur (UNS). Bahía Blanca. (Argentina)

E-mail: loreana.espasa@uns.edu.ar 
which allow for a deeper analysis and understanding of the prob-lem of illegal cocaine trafficking. The study is approached through the re-newed theoretical framework of Political Geography and Economic Geogra-phy, mainly rescuing the ideas proposed by Haesbaert (2013) about multiterri-toriality and mobility and, by Sack (1986) on the control of the territory. Re-garding the results of the research, the need to adopt an integrative territorial approach that allows a better understanding of the ways in which these illegal economies operate and interact, in the overlap of legal and illegal territories, is highlighted.

Keywords: Illegal geographies; cocaine trafficking; multi-scale and multiter-ritorial approach; South America-Caribbean.

\section{[fr] La problématique du trafic illicite de cocaïne dans une approche multiscalaire et multiterritoriale}

Résumé. L'objectif de ce travail est d'analyser le problème mondial du trafic illicite de cocaïne, à partir d'une approche multi-échelle et multi-territoriale qui identifie les dynamiques émergentes et leurs articulations multi-échelles. Une approche qualitative basée sur la méthode inductive est utilisée, qui est complétée par la consultation de sources secondaires, telles que des rapports d'organisations officielles et de la presse écrite, qui permettent une analyse et une compréhension plus approfondies du problème. L'étude est abordée à travers le cadre théorique renouvelé de la géographie politique et de la géographie économique, sauvant principalement les idées proposées par Haesbaert (2013) sur la multiterritorialité et la mobilité et, par Sack (1986) sur le contrôle du territoire. En ce qui concerne les résultats de la recherche, la nécessité d'adopter une approche territoriale intégrative qui permet de mieux comprendre les modes de fonctionnement et d'interaction de ces économies illégales, dans le chevauchement des territoires légaux et illégaux, est mise en évidence.

Mots clés: Géographies illégales; trafic de cocaïne; approche multi-échelles et multi territoriale; Amérique du Sud-Caraïbes.

Cómo citar. Guerrero, A.L. y Espasa, L.C. (2021): La problemática del tráfico ilegal de cocaína desde un enfoque multiescalar y multiterritorial. Anales de Geografía de la Universidad Complutense, 41(2), 343-364.

Sumario. 1. Introducción. 2. Breve marco teórico conceptual. 3. Narcotráfico y estado. Territorialidades emergentes a escala global. 4. Enfoque multiescalar y multiterritorial de la problemática del tráfico ilegal de cocaína en Latinoamérica. 4.1. El tráfico ilegal de cocaína en Latinoamérica. 4.2 Enfoque territorial del tráfico ilegal de cocaína. 5. A modo de conclusiones. 6 . Referencias bibliográficas.

\section{Introducción}

En el marco del Proyecto de Investigación "Geopolítica y Territorio. Procesos territoriales emergentes en la articulación local - global en América Latina" (Departamento de Geografía y Turismo. Universidad Nacional del Sur. (24/ G082), el presente trabajo propone estudiar la problemática global del tráfico ilegal de la cocaína desde un enfoque multiescalar y multiterritorial

Actualmente, como consecuencia de los cambios en la lógica espacial del capitalismo global, se está produciendo una rápida reconfiguración de los territorios. Este escenario se caracteriza por un modelo donde coexisten la Globalización y la Regionalización como hechos contradictorios y complementarios entre sí. La globalización vista como una hegemonía compartida a escala mundial, que concentra 
el poder económico, político y social en determinadas áreas, excluyendo a numerosos países. Mientras que la regionalización, se puede interpretar como el contrapeso al proceso globalizador (Guerrero, 2019:2).

El presente artículo destaca los retos que enfrenta el escenario global en relación con algunas economías ilegales que actúan a gran escala. Como sostienen Escobar y Rico (2019), una parte importante de estas economías se desarrolla en zonas rurales que presentan un rezago histórico y estructural, caracterizadas por la pobreza, la debilidad de las instituciones y la escasa efectividad de la seguridad pública. En este escenario, organizaciones criminales llegan a disputar las funciones del Estado en la provisión de bienes y servicios públicos, convirtiéndose en actores clave en dichos territorios. Se pone así de relieve la necesidad de adoptar un enfoque territorial integrador que permita comprender mejor las formas en que operan e interactúan estas economías ilegales, en la superposición de territorios legales e ilegales.

Siguiendo este argumento, entre los temas emergentes con impacto en el escenario global, se encuentran las estrategias territoriales del tráfico ilegal de cocaína, que plantean la necesidad de trabajar con nociones de territorialidad más dinámicas, a fin de analizar la complejidad de relaciones de poder establecidas entre actores que operan a distintas escalas. Esta complejidad requiere una interpretación crítica de la problemática que se propone abordar desde un enfoque multiescalar y multiterritorial para destejer el entramado de relaciones multiescalares y transescalares de poder, que se producen entre múltiples actores, en su articulación regional - global.

El narcotráfico es un problema global debido a los componentes transnacionales existentes en las etapas de producción, transporte y consumo de drogas ilícitas. Se ha convertido, en las últimas décadas, en un fenómeno de importancia creciente, no solo desde el punto de vista económico, dadas las cuantiosas ganancias que genera y las inversiones que surgen de ellas, sino también por su vinculación directa con diversas tipologías de conflictos, o por sus consecuencias sobre la fragilidad interna de diferentes Estados. Esta importancia deriva asimismo de la complejidad de su distribución geográfica, que se amplía de manera constante, observándose procesos de deslocalización, diversificación y división espacial del trabajo entre redes criminales que operan a escala transnacional (Méndez, 2011).

En este contexto, el marco teórico de la Geografía, a través del estudio de las denominadas Geografías Ilegales, brinda claves analíticas para comprender el funcionamiento espacial de actividades vinculadas al tráfico ilegal de diferentes mercancías, como armas, piedras preciosas y drogas. Asimismo, el enfoque territorial que surge de las nuevas conceptualizaciones de la Geografía Política y de la Geografía Económica, se complementa, en particular, con las ideas propuestas por Haesbaert (2013) de desterritorialización, multiterritorialidad y movilidad, junto con las ideas de Sack (1986) vinculadas con el control del territorio.

El incremento de las desigualdades existentes entre los territorios ha generado nuevos conflictos, que surgen a partir de los procesos de reestructuración socioespacial que realizan los actores. Se considera que territorio y red, así como espacio y tiempo no pueden ser disociados, puesto que actúan como elementos 
estructurantes y dinamizadores del espacio, en entornos cada vez más dinámicos y complejos, que impactan de forma diferencial en los diversos territorios.

En virtud de ello, reconociendo que América Latina es la región más desigual del planeta, es importante identificar qué factores influyen o son determinantes en las dinámicas territoriales emergentes. Se destaca que, mientras en algunos territorios emergen dinámicas territoriales "virtuosas", que llevan a generar desarrollo con bienestar e inclusión social, en otros, emergen las que denominamos dinámicas territoriales "perversas" como las producidas por el tráfico ilegal de cocaína. Éstas últimas a escala local, implican la formación de territorios donde se expande la criminalidad cuando los traficantes imponen sus intereses - por la fuerza - mediante la lógica del miedo como estrategia de dominación del territorio y su población. En tanto que, a escala regional - global, implican problemas de gobernanza territorial ya que generan pérdida de soberanía y control territorial que desestructuran el territorio legítimo del Estado - Nación (Colares de Couto, 2014, Colares de Couto, 2018).

En el marco del objetivo general del proyecto de investigación mencionado, que propone estudiar procesos y dinámicas territoriales emergentes en América Latina, resultantes de la articulación regional-global, desde una perspectiva geopolítica latinoamericana, se plantea como objetivo del presente trabajo analizar la problemática global del tráfico ilegal de cocaína, desde un enfoque multiescalar y multiterritorial que identifique las dinámicas territoriales emergentes $y$ sus articulaciones multiescalares. Este enfoque permite avanzar sobre trabajos previos de las autoras, en relación con la comprensión de la cadena global de valor de la cocaína, resaltando la fragmentación y la deslocalización como características distintivas de esta cadena.

En relación con la metodología, se plantea la investigación a partir del enfoque cualitativo, fundamentado en un método inductivo, dado que la aproximación al problema de investigación parte de estudios previos de las autoras, e investigación bibliográfica para conocer el estado de la cuestión. Se complementa con fuentes de información secundaria, documentos elaborados por organismos públicos y privados, así como prensa escrita junto a diversos sitios web. Ante la escasez de investigaciones aplicadas que recolecten información de manera sistemática, a una escala que permita establecer relaciones entre el ámbito local, regional y global, se resalta también la necesidad de incorporar artículos periodísticos de actualidad que muestren aspectos ilegales no registrados en los documentos oficiales, como los Informes sobre Drogas elaborados anualmente por la Oficina de Naciones Unidas contra la Droga y el Delito (UNODC).

Una limitante de estos informes oficiales, en relación con la problemática de las drogas ilícitas, es la falta de información sobre la producción de precursores químicos. Dichos informes hacen hincapié en otros datos, como superficie cultivada con hoja de coca, erradicación de cultivos, incautación de cargas, pero presentan dificultades para mostrar la producción de estas sustancias que resultan claves en el pasaje de la hoja de coca a cocaína. Así, se observa cómo el proceso de transformación presenta las mayores dificultades para obtener información al respecto, a pesar de tratarse de una fase clave en la producción de estas drogas. 
La escasez de datos acerca de las economías ilegales, impiden comprender el grado de complejidad que presentan y, por lo tanto, responder a los desafíos que plantean tanto por su naturaleza como por su interacción con otros ámbitos territoriales. Esta falencia en la información conduce a elaborar políticas públicas que no logran orientarse hacia acciones integrales y coordinadas que favorezcan el desarrollo de los Estados (sobre la base de Escobar y Rico, 2019).

El artículo se estructura en tres apartados: 1) Breve marco teórico conceptual 2) Narcotráfico y Estado. Territorialidades Emergentes a escala global; 3) Enfoque multiescalar y multiterritorial de la problemática del tráfico ilegal de cocaína en Latinoamérica.

\section{Breve marco teórico conceptual}

El renovado marco teórico que proporciona la Nueva Geografía Política permite abordar temas que anteriormente no eran incluidos en los estudios académicos, tal el caso de las investigaciones realizadas desde el enfoque de las denominadas Geografías Ilegales. Como sostiene Quintero (2007), este es un tema emergente de las problemáticas actuales de la sociedad, que plantea la necesidad de trabajar con nociones de territorialidad y poder -abiertas y flexibles- que permitan captar y analizar las complejas relaciones que se establecen entre los diferentes actores, que operan a distintas escalas y construyen territorialidades emergentes.

De este modo, para analizar desde un enfoque territorial las principales dinámicas territoriales emergentes derivadas del tráfico ilegal de cocaína en América Latina, se estudian cuestiones territoriales ligadas al poder. En este sentido, el territorio está vinculado siempre con el poder y con el control de procesos sociales mediante el control del espacio. Esta mirada implica una visión política del territorio, marcada por una tradición del concepto de territorio legal como territorio del Estado.

Siguiendo a Sack (1986, en Haesbaert, 2013) el territorio es todo espacio que tiene el acceso controlado; por lo tanto, desde el momento en que se controla espacial y materialmente el acceso de algún flujo (sea de mercancías, de personas o de capital), se está transformando el espacio en un territorio. La idea de Sack, que vincula el territorio con los procesos de control del espacio, la retoma Haesbaert, quien explica que el territorio se compone de redes que articulan distintos territorios a partir del movimiento y del tránsito de las personas y objetos, lo cual es clave para comprender un aspecto central del territorio: el control del espacio mediante el control de la movilidad (Haesbaert, 2013).

Por lo tanto, como sostiene Haesbaert (2013), la desterritorialización implicaría la disminución de los controles en el espacio, es decir, la superación de los controles territoriales. La propia concepción del debilitamiento del Estado pasaría entonces por la perspectiva del territorio en relación con el control de la accesibilidad. Por su parte, Basualdo, et al. (2019), sostienen que esta visión del territorio lleva a una concepción de poder vinculada directamente, por un lado, a quienes tienen el control de los flujos -pudiendo desencadenarlos, direccionarlos o limitarlos- y por el otro, a quienes no 
poseen ese control y sufren las tentativas de "inmovilización", aunque siempre de manera relativa. En este sentido, para Haesbaert, los procesos de contención territorial, "dibujan nuevas-viejas estrategias de control territorial", novedosas en sus formas contemporáneas pero antiguas en cuanto que los muros constituyen estrategias históricas de control.

Ampliando esta mirada de control de la movilidad Haesbaert (2013:26) señala que el territorio debe ser concebido como producto del movimiento combinado de desterritorialización y de reterritorialización, es decir, de las relaciones de poder construidas en y con el espacio, considerando el espacio como un constituyente, y no como algo que se pueda separar de las relaciones sociales.

De este modo, la desterritorialización nunca puede disociarse de la reterritorialización $\mathrm{y}$, puede tener tanto un sentido positivo como negativo, centrado en el papel de los actores sociales a través del tiempo, en las decisiones políticas adoptadas en cada contexto y en su impacto territorial.

Al enfoque territorial desde la Geografía Política se le suma el amplio marco conceptual de la Nueva Geografía Económica, que también brinda herramientas para comprender la complejidad actual de los territorios, en el marco de las transformaciones de la lógica espacial del capitalismo global. Los aportes de la Nueva Geografía Económica llevan a adoptar una concepción del espacio más flexible, en el cual los factores que explican el dinamismo de un territorio incorporan nociones de espacio de redes y espacios de flujos (Guerrero y Espasa, 2019).

De acuerdo con Blanco (2007) la perspectiva de las redes es útil para analizar las relaciones, la aceleración en la circulación de los flujos - personas, bienes, ideas, información capitales - que conectan los distintos actores y territorios formando un conjunto articulado. En este contexto, el análisis de las redes hace hincapié en la configuración de un espacio de relaciones en el que la red define un recorte territorial de referencia, convirtiéndose en el vehículo que vincula los procesos entre las diferentes escalas (Blanco, 2007 a, Blanco, 2007 b).

Asimismo, Haesbaert (2013), sostiene que los territorios se construyen mediante la articulación en red, y por lo tanto, pueden ser construidos también en y por el movimiento. Propone trabajar con dos lógicas de construcción del espacio: una zonal y otra reticular. Ambas operan siempre en forma conjunta, pero en determinados momentos y procesos y, para determinados actores, una de las lógicas puede predominar en relación con la otra. El Estado tiene una lógica más zonal, más de control de áreas o de superficies moldeadas en mayor medida por una lógica zonal de producción del espacio. En cambio, para el gran capital y las grandes empresas o las cadenas ilegales como el narcotráfico, la territorialidad se manifiesta en mayor medida en forma de red, porque su interés es controlar la movilidad a través de redes y flujos a fin de promover la circulación de mercancías y de capital.

La lógica reticular está mucho más presente en este tipo de territorialidad, pero, evidentemente, siempre articulada con la territorialidad zonal de los Estados-Nación. Por ello, Haesbaert (2013:34) sostiene que: la multiterritorialidad es la posibilidad de tener la experiencia simultánea y/o sucesiva de diferentes territorios, reconstruyendo constantemente el propio, mientras que en un sentido más estricto, puede significar la 
articulación simultánea de múltiples territorios o de territorios en sí mismos múltiples e híbridos.

En esta línea, Méndez (2011:177) agrega que el tráfico de drogas se asocia a la construcción de uno de estos espacios de redes que articula e interrelaciona el espacio de los lugares generando impactos diferentes en cada caso, cuyo sentido solo se alcanza a partir de una perspectiva multiescalar".

De este modo, entendiendo al territorio como una construcción social e histórica, se identifican procesos, conflictos, tensiones o contradicciones que se producen a partir de la interacción local-regional-global, en particular en espacios latinoamericanos, desde una visión compleja, multiescalar y multiterritorial (Guerrero, 2019).

\section{Narcotráfico y estado. Territorialidades emergentes a escala global}

El Informe Mundial sobre Drogas 2019 elaborado por UNODC, expresa en líneas generales preocupación por el incremento y persistencia en el consumo de drogas que se produce en el mundo junto a las amenazas que plantean estas sustancias ilícitas para la salud de los ciudadanos. Por otra parte, señala los efectos del narcotráfico en la economía mundial, así como la fuente de ingresos que supone para la financiación del terrorismo a escala global y para las redes delictivas organizadas. Estas redes no solo alientan la corrupción en los Estados débiles sino que la han convertido en un factor coadyuvante.

Ejemplo de ello es el pedido del gobierno de Estados Unidos -realizado el 26 de marzo de 2020- cuando ofreció una recompensa de 15 millones de dólares por información que lleve a la detención de Nicolás Maduro, la cúpula del gobierno y el alto mando de las Fuerzas Armadas venezolanas, acusando al régimen de tramar una conspiración con las fuerzas disidentes de la FARC para, en palabras del fiscal general William Barr, "inundar a Estados Unidos de drogas". Asimismo, como sostiene Geoffrey Berman, fiscal federal del distrito sur de Nueva York, "el alcance y la magnitud de la droga traficada solo fue posible porque Maduro y las instituciones corruptas de Venezuela proveyeron protección política y militar para los crímenes de narcoterrorismo". Además, sostuvo que "la cúpula chavista presionó a otros gobiernos de la región para que permitan el despliegue de la trama criminal" (Infobae, 26 de marzo 2020). Sin embargo, una pregunta que surge es por qué Estados Unidos acusa a Venezuela de "narcoestado" y no a Colombia, a pesar que en los informes de UNODC se menciona a Colombia como principal productor y distribuidor, mientras que Venezuela aparece solo como lugar de incautación.

En este contexto, estudiar las principales dinámicas territoriales emergentes derivadas del tráfico ilegal de cocaína, requiere considerar distintas visiones acerca de las cuestiones territoriales ligadas al poder. Así, algunos autores sostienen que las organizaciones ilegales están construyendo un tipo de territorialidad sustancialmente diferente a la de los territorios legales, con los cuales compiten (Nogué, 2006). 
Otros enfoques con una visión ampliada de la problemática, con los que coincide este artículo se oponen a la idea de trabajar con la hipótesis de un territorio legal (el estatal nacional) que se supone fijo, estable y organizado aun cuando permeable a la acción delictiva, y otros territorios ilegales (el del narcotráfico) superpuestos, móviles, inestables y en competencia con el primero, ya que resulta ineficaz para comprender los procesos reales de organización del espacio”, Quintero (2007:158).

Asimismo, en su trabajo sobre el tráfico ilegal de drogas en el Amazonas, Osorio Machado (2001:55-56, en Quintero, 2007) ha insistido en la necesidad metodológica de integrar en un mismo escenario territorial y conceptual, a los actores y prácticas legales e ilegales, y observar las analogías entre las prácticas de las organizaciones delictivas y, las de los actores políticos legítimos. De este modo, como sostienen Agnew et al, 2003 (en Quintero, 2007) las redes ilícitas coordinan actividades a través y alrededor de los territorios estatales eludiendo los controles fronterizos y desafiando la soberanía territorial.

Entonces, ¿por qué estudiar el tráfico ilegal de cocaína desde un enfoque multiescalar y multiterritorial? Porque por su carácter transnacional no solamente existen vínculos entre los narcotraficantes en Latinoamérica, como productores, distribuidores y transportistas, sino también por los nexos que se han creado con otros territorios debido a la liberalización del comercio internacional y regional, la inversión de capitales y una mayor movilidad de mercancías y personas. Estos factores han sido aprovechados por el narcotráfico, ampliando su capacidad operativa y económica, mediante el desarrollo de técnicas cada vez más sofisticadas para rebasar las capacidades de los controles fronterizos y de seguridad de los Estados. De allí la importancia de trabajar con nociones de territorialidad y poder -abiertas y flexibles- como sostiene Quintero (2007).

En este marco, en los últimos años se observa una clara expansión, tanto en términos geográficos como cualitativos, de la producción y consumo de drogas ilícitas -en particular de cocaína- y, en consecuencia, se han incorporado a este mercado nuevas regiones, a través de la ampliación y complejización de las redes de transporte. De este modo, el transporte opera a través de redes, organizadas mediante rutas que conectan los nodos entre espacios de producción, de tránsito y de consumo.

En el mapa de la Figura 1, se observa cómo las operaciones y la logística del tráfico internacional de drogas tienen una amplia flexibilidad en sus rutas y en su capacidad de adaptación a distintos entornos sociopolíticos, ampliando los hubs de distribución de la cocaína del Atlántico al Pacífico. Se destaca que las rutas de la cocaína sudamericana, procedente de la Región Andina -principal productora de cocaína a escala global- son diversificadas. Desde allí parten dos flujos principales: el más importante se dirige hacia Estados Unidos a través de América Central, Caribe y México y, el segundo en importancia, atraviesa el Atlántico y se dirige hacia Europa, en algunos casos vía África, que actúa como espacio de tránsito. Asimismo, otros flujos se dirigen, cada vez más, hacia los mercados asiáticos.

Una nueva ruta de la droga entre América y Oceanía, con escala en la Polinesia Francesa, se desarrolló en los últimos cinco años. Involucra a la cocaína y las metanfetaminas que se esconden en cascos de veleros en Estados Unidos y América 
Latina y se transportan hacia Australia, a través de las islas del Pacífico Sur (Lyons, 2020). En este sentido, es posible observar en el mapa elaborado por UNODC 2019 (Fig. 1) que si se traza una línea recta entre Bogotá y Canberra se verá cómo atraviesa las islas de la Polinesia. Además, Australia y Nueva Zelanda tienen los índices más altos de consumo de cocaína per cápita en el mundo y también pagan más por la droga que en otros lugares del planeta (aproximadamente 300 dólares australianos o unos 200 dólares por gramo), convirtiéndolo en un mercado lucrativo para el tráfico ilegal de cocaína ya que implica un flujo de miles de millones dólares (Lyons, 2020)

Figura 1. Principales rutas de tráfico de cocaína según las incautaciones comunicadas (20132017).

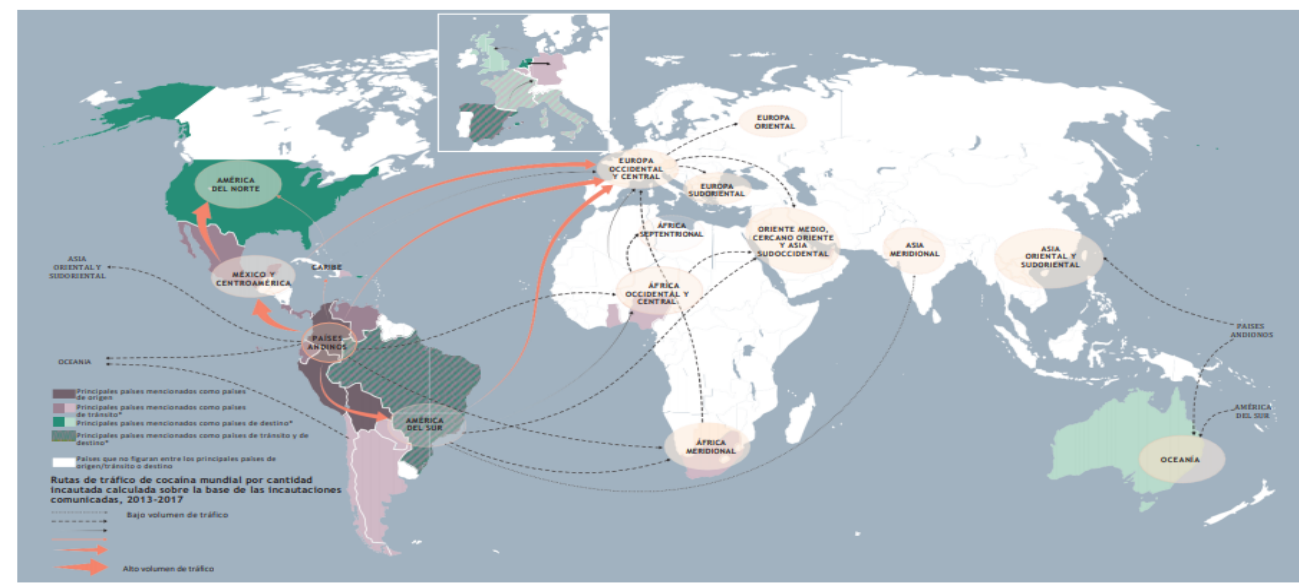

Fuente: Informe Mundial sobre las Droga, UNODC, 2019

Desde punto de vista económico, las ganancias derivadas de estas economías ilegales, explican el cambio de territorios sobre los que ejercen el control los distintos grupos de narcotraficantes. Los grupos colombianos cedieron sus operaciones en Estados Unidos a los cárteles mexicanos y se redirigieron hacia Europa y Asia por la diferencia en el precio por kilo de cocaína. Como se observa en los siguientes valores obtenidos de McDermott (2018), quien señala que los precios al por mayor en Estados Unidos oscilan entre 20.000 y 25.000 dólares por kilo, pero en Europa un kilo de cocaína vale 35.000 dólares, en China 50.000 dólares y en Australia 100.000 dólares.

La aparición de nuevas rutas y el desplazamiento hacia nuevos puertos, significa un crecimiento importante del poder del narcotráfico en otros países que se expresa en dos dimensiones. Por un lado, en el potenciamiento de redes de narcotraficantes locales que se van volviendo más poderosas $\mathrm{y}$, por otro, en la capacidad de reproducción económica que este tipo de mercado tiene en la economía legal e ilegal 
en los diferentes territorios a través de servicios logísticos, corrupción y lavado de dinero (Pontón, 2013).

Estas rutas ocultas del narcotráfico, visibilizadas a partir de la acción de control que realizan los Estados sobre su territorio, permiten ver de un modo concreto aquello que sostiene Haesbaert (2013) en cuanto a que, el territorio es producto del movimiento combinado de desterritorialización y de reterritorialización, a través de las relaciones de poder construidas en y con el espacio. De este modo, surgen territorialidades emergentes a escala global, en distintos territorios de Europa, Asia y Oceanía que pueden tener tanto un sentido positivo como negativo, dependiendo desde qué actor social / organización legal o ilegal -Estado o Narcotráfico - se analizan sus acciones a través del tiempo y cuál es su impacto en la sociedad y el territorio.

\section{Enfoque multiescalar y multiterritorial de la problemática del tráfico ilegal de cocaína en latinoamérica}

Al analizar las cuestiones ligadas al narcotráfico, dado su carácter transnacional, es posible proponer una regionalización de Latinoamérica, de acuerdo con los objetivos de la presente investigación, en función de las zonas de producción, tránsito, distribución y consumo. La Región Sudamericana, integrada por la Región Andina (zona de producción), la Amazonía y el Cono Sur (zonas de tránsito, distribución y consumo) y, la Región Caribe que actúa, principalmente, como zona de tránsito y distribución. De este modo, se busca identificar el anclaje territorial del tráfico ilegal de la cocaína en Latinoamérica.

\subsection{El tráfico ilegal de cocaína en Latinoamérica}

En el contexto de la Región Sudamericana es posible diferenciar dos zonas: la zona de producción tradicional de hoja de coca, integrada por los países de la Región Andina, donde se destacan Bolivia, Perú y Colombia como mayores productores a nivel mundial, y la zona de distribución y consumo, conformada por Argentina, Brasil, Ecuador y Venezuela que se han convertido en países de tránsito de cocaína, dado que cuentan con sistemas de transporte sin la vigilancia apropiada para interceptar la droga en las fronteras y en los puertos (Emmerich, 2015).

En la Región Andina, de acuerdo con el Informe 2018 de UNODC, la superficie cultivada con arbusto de coca en los últimos 12 años se ha mantenido en un promedio de 150.000 hectáreas anuales, con la excepción de una caída entre 2012 y 2014. Los datos sostienen que la superficie cultivada con arbusto de coca en la Región en 2017 llegó a las 245.000 hectáreas, un 15\% mayor a la reportada en 2016 . En el caso de Perú tuvo un incremento del 14\% (de 43.900 ha. en 2016 a 49.900 en 2017). En Bolivia, por su parte, el área cocalera se ha incrementado en un $6 \%$ (de 23.100 a 24.500 ha.) mientras que en Colombia, la variación indica un aumento del 17\% (de 146.000 a 171.000 ha.) (Figura 2). Con esta hoja de coca sembrada se produjeron 
1.410 toneladas de clorhidrato de cocaína, consumidos por aproximadamente 18 millones de personas en el mundo.

Figura 2. Hectáreas cultivadas con arbusto de coca (1996 - 2017).

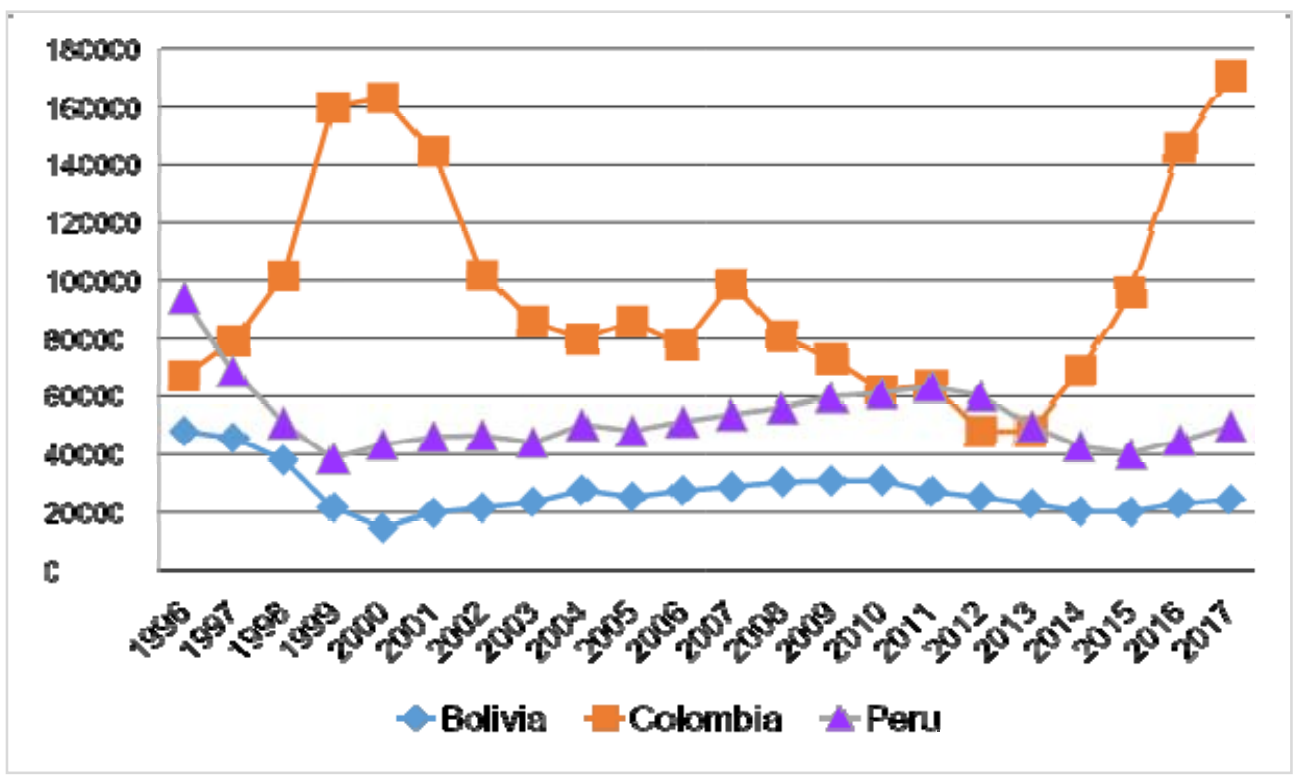

Fuente: Guerrero y Espasa, 2020 sobre la base de Informes UNDOC 2010, 2016 y 2018

Según Pastor Gómez (2020:213) este incremento en la expansión de los cultivos de arbusto de coca en la Región Andina se debió a tres dinámicas principales producidas en Colombia: a) La suspensión gubernamental, a partir de mayo de 2015, de las fumigaciones aéreas de los cultivos de coca por sus efectos sobre la salud de la población; b) En ese mismo año, miembros de las FARC, viendo próximo el acuerdo de paz con el gobierno, promovieron la siembra de más cultivos de coca, con el doble objetivo de reunir la mayor cantidad de dinero posible antes de abandonar la economía ilegal y de fortalecer su posición en la mesa negociadora, argumentando que la única forma que tenía el gobierno de controlar los cultivos de coca era con la ayuda de las FARC; c) A partir del año 2016, se comienza a cultivar el arbusto de coca en zonas donde no se había cultivado previamente, con apoyo de otros grupos delictivos organizados y/o el Ejército de Liberación Nacional (ELN).

Como consecuencia, de acuerdo con los datos aportados por el Informe 2019 de UNODC, en la etapa siguiente, que transforma la hoja de coca en cocaína, Colombia se convirtió en el primer país productor de cocaína del mundo. Su producción, que se había reducido prácticamente a la mitad entre 2006-2013, aumentó un $56 \%$ entre 2013 y 2016 y un 25 \% más entre 2016 y 2017, momento en que alcanzó un máximo histórico de 1.976 toneladas de cocaína, aproximadamente el $70 \%$ de la cocaína mundial (UNODC, 2019). El mismo Informe explica que este aumento de la 
productividad de clorhidrato de cocaína pura se debe a que el método colombiano es más eficiente que el peruano y el boliviano en cuanto a la extracción del alcaloide. Aquí se evidencia la importancia de los precursores químicos en el proceso de producción de cocaína, a pesar de la falta de información en relación con ellos.

La investigación realizada permite identificar determinadas áreas a las que denominamos "zonas grises". Son aquellas marginadas de la acción del Estado, donde se incrementa la presencia de redes ilegales que toman el control del territorio, generando una reestructuración del mismo en función de sus intereses, facilitada por la porosidad de las fronteras. En estas zonas se evidencia la necesidad de estudiar en forma integrada los territorios legales (definidos por los límites políticoadministrativos de los Estados) y los territorios ilegales donde el narcotráfico ejerce el control de la movilidad. De esta manera. se visibilizan las ideas de multiterritorialidad y movilidad propuestas por Haesbaert (2013) así como la idea de control del territorio de Sack (1986).

Estas zonas grises se encuentran relativamente cercanas a centros poblados, nodos de mercados y servicios. Son zonas geográficamente complejas (montañosas o selvas tropicales húmedas) donde la infraestructura vial y la navegabilidad fluvial son muy precarias y costosas. Una de estas áreas se localiza, en el interior de la Región Sudamericana, en la franja fronteriza que articula la Amazonía con diferentes Estados (Colombia, Bolivia, Perú, Venezuela, Ecuador y Brasil) en la cual la acción del narcotráfico se ve favorecida por una débil presencia del Estado, la existencia de vacíos demográficos junto a débiles sistemas de control y comunicación.

Otro ejemplo de estas zonas grises se puede observar en el caso de Perú, de acuerdo con el Programa de Monitoreo de Cultivos Ilícitos de la UNODC de 2017, según el cual se evidencia un desplazamiento del cultivo de arbusto de coca hacia las fronteras con Brasil y Bolivia, originando un cambio en el mapa peruano de la coca. Este desplazamiento ha obligado a una reestructuración de las redes de transporte en dos ejes: vía terrestre y vía aérea. En cuanto a las exportaciones de hoja de coca por vía terrestre, se realizan a través de la frontera con Bolivia, donde se emplean precursores químicos para su transformación en cocaína y luego, se exporta hacia los mercados emergentes de Asia por los principales puertos del país: El Callao y Paita. De acuerdo con el mismo informe, en estos puertos, se paga 2.000 dólares por cada kilogramo de cocaína que viaja, de forma ilegal, escondido en los contenedores.

En cuanto a la segunda modalidad, se ha establecido un puente aéreo entre Perú y Bolivia en el cual se utilizan "narcoavionetas" para exportar la droga a Brasil. Las razones que explican este desplazamiento tienen que ver con la reconfiguración de los mercados del Cono Sur donde Argentina, Brasil y Chile se han convertido en puntos de reembarque hacia otros destinos, debido al aumento en el consumo de cocaína en la región y en el mundo. De esta manera se observa cómo el desplazamiento de los cultivos se realiza en función de las posibilidades de las redes de transporte para facilitar el acceso a mercados emergentes. 
Figura 3: Zonas grises en la Región Sudamericana.

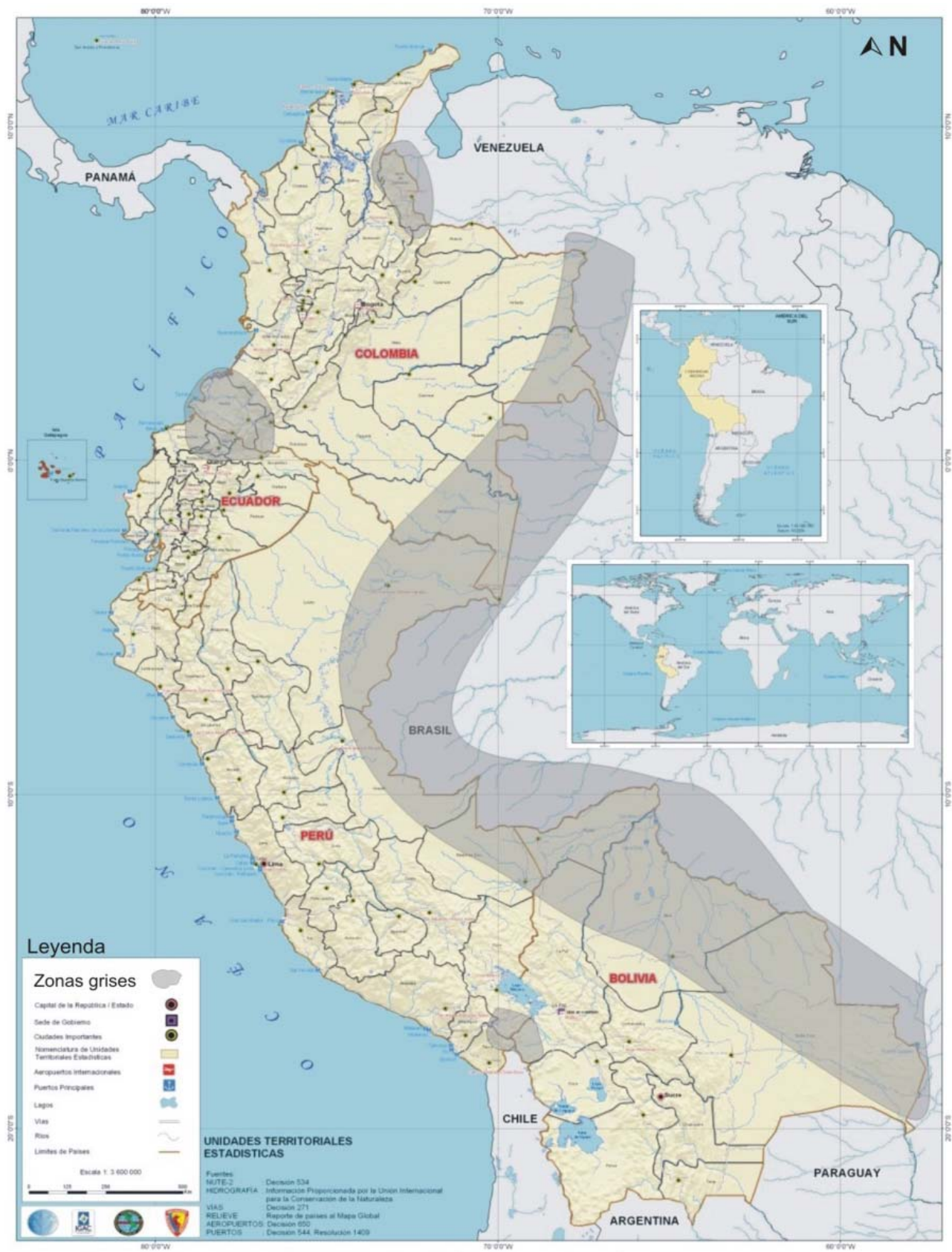

Fuente: Espasa, L.C. (2020), sobre la base de investigaciones realizadas en Guerrero, A.L. y Espasa, L.C. (2020). Base cartográfica: Comunidad Andina. 
Asimismo, otra de las zonas grises identificadas se encuentra en Colombia dónde, según Pastor Gómez (2020), existen en la actualidad dos zonas principales de cultivo de la hoja de coca y de transformación en cocaína localizados en el Departamento de Nariño, situado sobre la costa del Pacífico, en la frontera con Ecuador (país costero y productor de petróleo) lo cual facilita tanto el transporte por mar, como el acceso a precursores químicos procedentes del petróleo para el procesamiento de la droga. El segundo Departamento productor más importante de Colombia es el denominado Norte de Santander, próximo a la frontera con Venezuela, donde resulta más barato producir cocaína, debido tanto a mejores condiciones para el cultivo, como a las múltiples facilidades existentes para adquirir combustible venezolano a bajo precio. En 2016, ambos departamentos representaron casi la mitad del crecimiento de la coca en todo el país. La Figura 3 muestra la localización de las diferentes zonas grises identificadas en la Región Sudamericana.

La última zona gris identificada es la que articula la Región Sudamericana con el Caribe a través de Venezuela. Como sostiene Pastor Gómez (2020) el narcotráfico encuentra en el Caribe ventajas debido a la múltiple soberanía de sus islas, lo que le permite operar desde dependencias francesas, holandesas, británicas o estadounidenses, y esto facilita la introducción de la cocaína en los países de destino como se observa en la Figura 4. A través de estas rutas circulan entre 200 y 250 toneladas métricas de cocaína, que equivalen hasta a 30 millones de dosis, según estimaciones del fiscal general de Estados Unidos, William Barr (2020).

Figura 4. Principales rutas del narcotráfico en el Caribe.

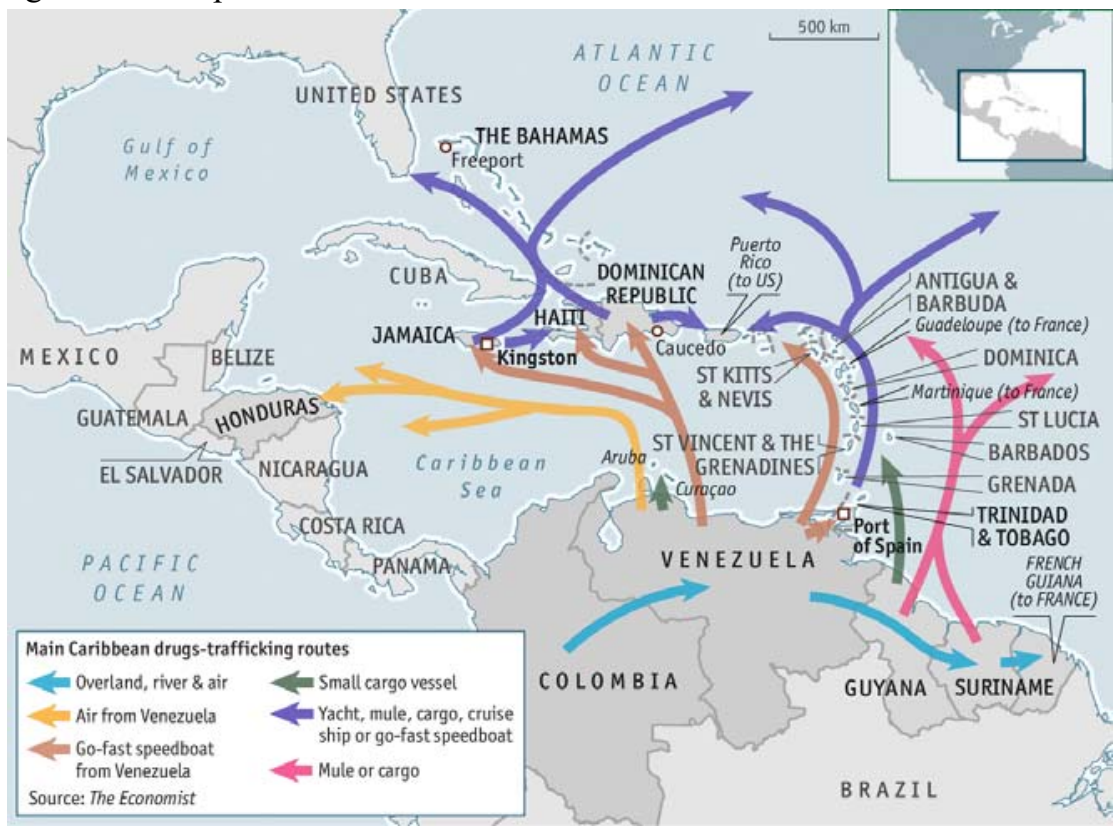

Fuente: The Economist (24/05/2014). 
Una de estas rutas es la que va directamente desde Colombia a Venezuela y desde allí se dirige hacia República Dominicana, que recibe un flujo anual de cinco millones de turistas y cuenta con seis puertos que la convierten en un centro regional para el transporte marítimo (Lyons,2020). Además, su destacada actividad económica, vinculada con el turismo, facilita el lavado del dinero obtenido por los narcotraficantes. Las rutas se dirigen luego hacia Estados Unidos o Europa mediante diferentes tipos de transporte.

En este contexto, la investigación realizada, permite afirmar que la imagen del territorio que muestran las cartografías de los informes oficiales (estática, fija y delimitada), apoyada en límites político - administrativos, es parcial puesto que se invisibilizan las disputas de poder por el control territorial de la movilidad entre diferentes actores y prácticas legales e ilegales. Por ello, se insiste en la necesidad metodológica de integrarlos en un mismo escenario territorial y conceptual, a fin de comparar las prácticas de organizaciones delictivas con las prácticas de actores políticos legítimos, tal como se explicó al identificar las zonas grises del tráfico de drogas en Sudamérica.

\subsection{Enfoque territorial del tráfico ilegal de cocaína}

Las estrategias del tráfico ilegal de cocaína pueden analizarse de dos maneras: a) desde un punto de vista económico, poniendo énfasis en la cadena global de valor (Guerrero y Espasa, 2019), haciendo hincapié en cada uno de los eslabones que intervienen en su producción, transformación y comercialización; o b) desde un punto de vista territorial, como el propuesto en esta investigación, donde se identifican, a través de la multiescalaridad y la multierritorialidad, la localización y los flujos del tráfico ilegal de la cocaína.

Un abordaje de esta cuestión, desde el punto de vista del funcionamiento los mercados, es el que realiza Emmerich (2015), el cual se reinterpreta, desde un enfoque territorial que propone estudiar los territorios de la producción, territorios de tránsito y territorios de consumo, reconociendo que el narcotráfico involucra múltiples territorios, que operan de forma integrada. En estos territorios el monopolio estatal del control de la movilidad está en disputa y existe un control territorial ejercido por el narcotráfico, lo cual es una condición que favorece el desarrollo de economías ilegales. De este modo, se confirma lo señalado en el marco teórico en cuanto a la necesidad de estudiar de forma integrada en un mismo escenario territorial a los actores y prácticas legales e ilegales.

Los territorios de producción se concentran en la Región Andina (Bolivia, Perú y Colombia) y comprenden tanto los países productores de hoja de coca como aquellos donde se la transforma en cocaína. Aunque sólo se produce coca en tres países de la región, esta actividad representa un problema estructural en los territorios productores, dado que se ha convertido en un factor clave para el desarrollo del narcotráfico. Otros factores coadyuvantes son la debilidad institucional de los Estados, los escasos controles en las zonas de producción, tránsito y comercialización, la 
presencia de una significativa mano de obra rural. La suma de todos estos factores contribuyó para que la región alcanzara protagonismo global en relación con la producción de cocaína.

Los territorios de producción se caracterizan por contar con bajos niveles de presencia estatal en funciones esenciales de seguridad, justicia, provisión de bienes y servicios y marcos regulatorios y, en consecuencia, de inversión, generando así sistemas de incentivo para la informalidad. Por ello, los actores ilegales, aprovechan la oportunidad que ofrece la debilidad institucional en estos territorios (Escobar y Rico, 2019). Se crean así monopolios en un encadenamiento de procesos que van desde el cultivo y la cosecha de la hoja, a la extracción de la pasta en laboratorios clandestinos dispersos por el territorio, la transformación en base de coca $y$, finalmente su conversión en clorhidrato de cocaína.

En cuanto los territorios de tránsito, se caracterizan por la circulación de distintos tipos de flujos que los atraviesan (hoja de coca, precursores químicos, pasta base de cocaína, dinero). Tal como se mencionara en la Región Sudamericana, Argentina, Brasil, Ecuador y Venezuela se han convertido en países de tránsito de cocaína, dado que cuentan con sistemas de transporte sin la vigilancia apropiada para interceptar la droga en las fronteras y en los puertos. Teniendo en cuenta la diversificación de las rutas de la cocaína sudamericana, se observa una estrecha articulación entre los territorios de tránsito del ámbito regional con los territorios de tránsito que operan a escala global. Estos territorios de tránsito son flexibles, en tanto buscan eludir controles estatales a la vez que adaptarse a los variables requerimientos de los mercados.

En los territorios de tránsito circulan también flujos de dinero provenientes del narcotráfico que resultan muy difíciles de identificar. En parte, porque el funcionamiento del sistema financiero global brinda herramientas legales para el blanqueo de dinero a través de los paraísos fiscales, y en parte porque el dinero generado se invierte en el circuito de la economía formal. En este sentido, un sistema financiero/bancario desarrollado con leyes de inversión permisivas y fuertes reglas de confidencialidad, constituye un instrumento clave para el crecimiento del narcotráfico.

En este sentido, Méndez (2011) identifica tres destinos principales para la penetración del dinero obtenido del narcotráfico en los circuitos de la economía legal. Una parte se destina a la adquisición de bienes de consumo muebles e inmuebles y se reinvierte en las áreas productoras, donde permite dinamizar determinados sectores (desde el inmobiliario al turístico, entre otros) Otra parte, generalmente mayor, se invierte en los territorios de consumo que, al tener economías más robustas, hacen que las inversiones pasen más fácilmente desapercibidas, al diversificarse en múltiples actividades, mientras que otra porción se deposita en la banca internacional y se reinvierte en operaciones bursátiles de todo tipo.

Finalmente, en los territorios de tránsito se resalta la importancia del factor geográfico, ya que en general se encuentran próximos o comparten fronteras con territorios productores y territorios consumidores, como se evidencia en el caso de las zonas grises de la Región Sudamericana donde se articulan las fronteras entre la Región Andina, la Amazonia y el Caribe. 
Por último, en los territorios de consumo se genera la mayor parte del valor agregado y es donde aumentan, considerablemente, los márgenes de ganancia. Estados Unidos y Europa Occidental aparecen como los mercados de consumo tradicionalmente más importantes para la cocaína producida en la Región Andina. Sin embargo, en los últimos años se está produciendo una expansión del consumo en los países sudamericanos como consecuencia del efecto derrame de constituirse en territorios de tránsito, así como los territorios de Asia Oriental y Sudoriental y en particular, Australia, como se observa en la figura 1.

Tabla 1. Caracterización de los territorios del tráfico ilegal de cocaína.

\begin{tabular}{|c|c|}
\hline & $\begin{array}{l}\text { * Producto agrícola de fácil producción y alta productividad. } \\
\text { * Empleo de gran cantidad de mano de obra en áreas rurales } \\
\text { * Marginación histórica de los productores de hoja de coca } \\
\text { *Abandono del control territorial de las zonas de producción por parte } \\
\text { de los narcos y delegación en otros actores. } \\
\text { *Presencia de organizaciones guerrilleras como intermediarias entre } \\
\text { los campesinos y los narcotraficantes } \\
\text { *Existencia de amplias regiones con autonomía geográfica que quedan } \\
\text { fuera del control del Estado (Zonas de frontera, zonas grises) }\end{array}$ \\
\hline $\begin{array}{l}\text { Territorios de } \\
\text { tránsito }\end{array}$ & $\begin{array}{l}\text { *Los narcotraficantes se han alejado de la producción y se están } \\
\text { dedicando cada vez más al tránsito, especializándose en el refinamiento y } \\
\text { en el transporte de la cocaína hacia la zona de destino } \\
\text { *Se produce un efecto derrame: a veces el narcotráfico no paga con } \\
\text { dinero, sino con droga en los niveles más bajos de comercialización del } \\
\text { producto. } \\
\text { *Son flexibles, en tanto buscan eludir controles estatales a la vez que } \\
\text { adaptarse a los variables requerimientos de los mercados. } \\
\text { *Cuentan con una relativamente buena infraestructura para la } \\
\text { circulación, facilitada por la debilidad de los organismos de control estatal } \\
\text { *Las zonas de frontera, se convierten en zonas grises, adquiriendo un } \\
\text { papel relevante en la circulación de la cocaína. } \\
\text { *También operan como territorios de flujo de las ganancias obtenidas } \\
\text { por el narcotráfico en los territorios de consumo. }\end{array}$ \\
\hline $\begin{array}{l}\text { Territorios de } \\
\text { consumo }\end{array}$ & $\begin{array}{l}\text { *Se genera la mayor parte del valor agregado en el microtráfico } \\
\text { *Se vincula con la aparición y el rápido desarrollo de la violencia y del } \\
\text { crimen organizado en las ciudades. } \\
\text { *Cobra-principal importancia el control territorial: alto nivel de } \\
\text { competencia entre distintas organizaciones } \\
\text { *El control territorial suele realizarse en complicidad con autoridades } \\
\text { policiales, judiciales y políticas de la zona. }\end{array}$ \\
\hline
\end{tabular}

Fuente: Guerrero, A.L. y Espasa, L.C. (2020) sobre la base de Méndez (2011) y Emmrich (2015) 
Los circuitos del narcotráfico desarrollados a escala global y regional, impactan en el territorio a escala local. En estos territorios tiene lugar el microtráfico, que se caracteriza por ser un mercado muy complejo con un alto grado de competencia entre la oferta y la demanda, que deriva en un elevado índice de criminalidad. En este mercado cobra principal importancia el control territorial que suele realizarse en complicidad con las autoridades policiales, judiciales y políticas de la zona (Emmrich, 2015). La siguiente tabla sintetiza las principales características de cada uno de los territorios identificados (Tabla 1).

El estudio de los territorios de producción, tránsito y consumo, debe ser abordado desde un enfoque integral, considerando que los territorios legales e ilegales, en la práctica, funcionan de manera interrelacionada conformando territorialidades superpuestas en las que resulta difícil separar los límites de acción de cada una de ellas.

\section{A modo de conclusiones}

El narcotráfico es un problema global debido a los componentes transnacionales existentes en las diferentes etapas de producción, transporte, distribución y consumo de drogas ilícitas. En este contexto, la investigación se propuso analizar la problemática del tráfico ilegal de cocaína desde un enfoque multiescalar y multiterritorial y, para ello recurrió al estudio de las denominadas Geografías Ilegales, que aportan a la comprensión del funcionamiento espacial de esta actividad. Se trabajó con nociones de territorialidad y poder -abiertas y flexibles- que permitieron captar y analizar las complejas relaciones que se establecen entre los diferentes actores estatales y no estatales, que operan a distintas escalas y construyen territorialidades emergentes.

De este modo, entendiendo al territorio como una construcción social e histórica, se identificaron procesos, tensiones o contradicciones que se producen a partir de la interacción local-regional-global, en particular en espacios latinoamericanos, desde una visión compleja, multiescalar y multiterritorial (Guerrero, 2019). Este enfoque territorial permite superar el sesgo económico dominante en las investigaciones sobre esta problemática.

Además, esta perspectiva territorial ligada al poder, vincula a quienes tienen el control de los flujos o la movilidad (actores estatales o no estatales, legales o ilegales) con quienes no poseen ese control. Para Haesbaert (2013), los procesos de contención territorial actuales, "dibujan nuevas-viejas estrategias de control territorial". En este sentido, las nuevas estrategias se centran en el control de la movilidad en relación con flujos dinámicos que la refuerzan, manejados más por el narcotráfico, que por el Estado, frente a las antiguas estrategias históricas de control estático a través de muros.

Al analizar las cuestiones ligadas al narcotráfico, desde un enfoque territorial, se identificó el anclaje territorial de las diferentes etapas de producción, distribución y consumo de la droga en Latinoamérica. Se reconocieron dos grandes regiones: la 
primera, la Región Sudamericana, integrada por la Región Andina, la Amazonía y el Cono Sur y, la segunda, conformada por el Caribe que actúa como zona de tránsito y distribución. Dentro de ellas, se identificaron "zonas grises" marginadas de la acción del Estado, facilitadas por la porosidad de las fronteras a escala regional y, su articulación con la escala global.

Asimismo, a partir del análisis multiescalar surgen territorialidades emergentes a escala global, que se articulan, a través de nuevas rutas, con territorios de Europa, África, Asia y Oceanía. Esta reconfiguración de las rutas puede tener tanto un sentido positivo como negativo, en función de las relaciones que se establezcan, a través del tiempo, entre Estado -narcotráfico y su impacto en la sociedad y el territorio.

De este modo, desde una visión integral de los territorios legales e ilegales se observa que el territorio como espacio complejo se organiza en forma simultánea y contradictoria. El Estado, en tanto territorio legal, (fijo, estable y organizado) y el territorio ilegal del narcotráfico (superpuesto, móvil e inestable) se solapan en el mismo espacio, reflejando tanto la multiterritorialidad expresada por Haesbaert (2013) como la articulación simultánea de múltiples territorios o de territorios múltiples e híbridos. Así, el territorio legal del Estado, cuando éste pierde el control de la movilidad, se vuelve permeable a la acción delictiva $\mathrm{y}$, el territorio ilegal del narcotráfico, entra en competencia con el primero, todo ello de forma integrada.

Asimismo, se hizo evidente lo expresado por Haesbaert (2013), en relación con la forma en la cual los territorios pueden ser construidos mediante la articulación en red y, por lo tanto, pueden construirse también en y por el movimiento, a través de dos lógicas de construcción del espacio: una zonal (la del Estado) y otra reticular (la del narcotráfico). A pesar que ambas operan siempre en forma conjunta, en determinados momentos y procesos y, para determinados actores, una de las lógicas puede predominar en relación con la otra.

En el caso estudiado, se pudo observar cómo el Estado tiene una lógica más zonal, más de control de áreas o de superficies moldeadas, en mayor medida, por una lógica zonal de producción del espacio con límites fijos en el territorio, mientras que, en las cadenas ilegales como el narcotráfico, la territorialidad se manifiesta en forma de red, porque su interés es controlar la movilidad a través de redes y flujos a fin de promover la circulación de mercancías y de capital.

En este sentido, del estudio realizado surge que, en algunos territorios emergen dinámicas territoriales, no "virtuosas" sino "perversas", producidas por el tráfico ilegal de cocaína. A escala local, son los territorios del microtráfico donde se expande la criminalidad mediante la lógica del miedo como estrategia de dominación del territorio y su población. En tanto que, a escala regional/global, se observa una pérdida del control territorial de la movilidad, que pasa a ser dominado por el narcotráfico y que implica desestructurar el control del territorio legal del Estado.

A través de los resultados obtenidos se pudo observar cómo se generan flujos, de mercadería y de dinero, en los territorios de distribución que conforman rutas diversas y flexibles- que configuran las redes del mercado ilegal de la cocaína. Se resaltó también cómo los flujos transfronterizos se relacionan, no solo con la forma en 
la cual circulan las drogas ilícitas, sino también con los actores, las estrategias y las diversas actividades que comprende el narcotráfico.

En conclusión, se puede afirmar que las organizaciones criminales como el narcotráfico, llegan a disputar las funciones del Estado en cuanto al control de la movilidad, convirtiéndose así en actores clave en el territorio. De esta manera, se pone en evidencia la necesidad de adoptar, por un lado, un enfoque multiescalar puesto que, la escala de análisis tradicional centrada en el Estado como único actor, ya no resulta funcional para el estudio de espacios complejos con la presencia de múltiples actores. Por otro lado, incorporar también una perspectiva multiterritorial que considere las relaciones transescalares de poder, definiendo quién ejerce el real control territorial de la movilidad.

En relación con la escasez de investigaciones aplicadas que recolecten información de manera sistemática, esta investigación realiza un aporte para la producción de conocimiento en el marco de las Geografías Ilegales. Sin embargo, dado el carácter ilegal de estas actividades, se presentan algunas limitaciones para su estudio ya que, más allá de la disponibilidad de informes oficiales, se torna necesario complementar con otras fuentes no oficiales, tales como artículos periodísticos de actualidad, que muestren aspectos ilegales no registrados en dichos documentos.

A modo de cierre, es posible aplicar este enfoque multiescalar y multiterritorial en otras investigaciones, así como establecer un diálogo con futuros trabajos, en otros espacios y con otros productos, que constituyan problemáticas globales o regionales de análisis. En consecuencia, se confirma la utilidad de un enfoque territorial integrador que permita comprender mejor la problemática del tráfico ilegal de la cocaína, considerando la imbricación existente entre territorios legales e ilegales.

\section{Referencias bibliográficas}

Basualdo, L; Domenech, E; Pérez, Evangelina (2019) Territorios de la movilidad en disputa: cartografías críticas para el análisis de las migraciones y las fronteras en el espacio sudamericano. Revista Interdisciplinar da Movilidade Humana, 57, 43-60.

Blanco, J. (2007 a) La Geografía de las redes. En: Fernández Caso, Ma. V. (coord.) Geografías y Territorios en transformación. Editorial Noveduc. Ciudad Autónoma de Buenos Aires.

Blanco, J. (2007 b). Espacio y territorio: elementos teórico conceptuales implicados en el análisis geográfico. En: Fernández Caso, Ma. V; Gurevich, R. (coord.) Geografía: nuevos temas, nuevas preguntas. Editorial Biblos. Ciudad Autónoma de Buenos Aires.

Colares de Couto, A. (2014). A geografia do crime na metrópole: das redes ilegais à territorialização perversa na periferia de Belém. Belén. EDUEPA.

Colares de Couto, A. (2014). Geopolítica, frontera e redes ilegais na Amazônia. Anales del I Congresso Brasileiro de Geografia Política, Geopolítica e Gestão do Território. Rio de Janeiro.Porto Alegre: Editora Letra1, p. 807-815.

Colares de Couto, A. (2018). Territórios-rede e territórios-zona do narcotráfico na me-trópole de Belém. GeoTextos, vol. 14, n. 1, Pp. 61-82. 
Emmerich. N. (2015). Geopolítica del narcotráfico en América Latina. IAPEM: Instituto de Administración Pública del Estado de México. Toluca, México.

Escobar, M. y Rico, D. (2019). La producción y explotación ilegales de materias primas en las zonas rurales de América Latina y sus líneas de impacto en el desarrollo territorial. 2030 Alimentación, agricultura y desarrollo rural en América Latina y el Caribe, No. 27. Santiago de Chile. FAO. 21 p.

Guerrero, A. L. (2016). Nueva Geopolítica de la energía en la Región Sudamericana. Ac-tores, tendencias y conflictos en la industria del gas. Tesis Doctorado en Geogra-fía. Bahía Blanca, Argentina. Universidad Nacional del Sur, Departamento de Geo-grafía y Turismo, 396 pp.

Guerrero, A. L. (2019). Reconfiguración de la integración en América en entornos geopolíticos dinámicos y complejos. VIII Congreso Nacional de Geografía de Universidades Públicas y XXI Jornadas de Geografía de la Universidad Nacional de La Plata. Facultad de Humanidades y Ciencias de la Educación. La Plata 9, 10 y 11 de octubre.

Guerrero, A. L.; Espasa, L. C. (2019). Geografías ilegales. La articulación de la Región Andina en la cadena global de valor de la cocaína. VIII Congreso Nacional de Geografía de Universidades Públicas y XXI Jornadas de Geografía de la Universidad Nacional de La Plata. Facultad de Humanidades y Ciencias de la Educación. La Plata 9, 10 y 11 de octubre. Haesbaert, R. (2013). Del mito de la desterritorialización a la multiterritorialidad. Cultu-ra y representaciones sociales. Año 8, n.15.

Infobae 26/03/ 2020.

https:/www.infobae.com/america/venezuela/2020/03/26/estados-unidos-sancionara-alregimen-de-nicolas-maduro-por-sus-vinculos-con-el-narcoterrorismo-internacional/

Lyons, K. (2020) Clarín, https://www.clarin.com/mundo/nueva-ruta-droga-veleros-americaoceania-haciendo-estragos-paraiso_0_-x8biLpyu.html

McDermott, J. (2018). La nueva generación de narcotraficantes colombianos post-FARC: Los invisibles». Insighy Crime pp. 4 y 17.

Méndez Gutiérrez del Valle, R. (2011). El nuevo mapa geopolítico del mundo. Valencia. Editorial Tirant Lo Blanch.

Nogué, J. (2006) Geografia política. En: Hiernaux, D.; Lindon, A. (eds.) Tratado de Geografía Humana. Editorial Antrophos. Barcelona.

Oficina de las Naciones Unidas contra la Droga y el Delito (UNODC) (2010) Informe Mundial sobre las Drogas.

Oficina de las Naciones Unidas contra la Droga y el Delito (UNODC) (2018) Informe Mundial sobre las Drogas

Oficina de las Naciones Unidas contra la Droga y el Delito (UNODC) (2018) Monitoreo de Cyltivos de coca 2017. Perú.

Pastor Gómez, M.L. (2020) El mar Caribe, el narcotráfico y los «nuevos piratas» en Panorama geopolítico de los conflictos 2019, pp.199-220. Ministerio de Defensa, Instituto Español de Estudios Estratégicos, España.

Pontón, D (2013). La economía del narcotráfico y su dinámica en América Latina. Íco-nos. Revista de Ciencias Sociales. Num. 47. Pp 135-153. Facultad Latinoamericana de Ciencias Sociales, Quito, Ecuador. 
Quintero, S. (2007): Territorio, gobierno y gestión. En: Fernández Caso, Ma.V.; Gure-vich, R. Geografía, nuevos temas, nuevas preguntas. Ciudad Autónoma de Buenos Aires. Ed. Biblos.

The Economist, 24/05/2014 "Drugs trafficking in the Caribbean. Full circle". Recupera-do de: https://www.economist.com/the-americas/2014/05/24/full-circle 